\title{
Qualidade fisiológica de sementes de milho doce classificadas pela espessura e largura ${ }^{1}$
}

\author{
Claudemir Zucareli², Cristian Rafael Brzezinski², \\ Josiane Marlle Guiscem ${ }^{3}$, Fernando Augusto Henning ${ }^{4}$, João Nakagawa ${ }^{5}$
}

\begin{abstract}
Physiologic quality of sweet maize seeds according to thickness and width

Sweet maize seeds present lower physiologic quality, when compared to regular maize seeds, due to the influence of several features, such as the seed size and shape. Thus, this study aimed at evaluating the seed physiologic quality of two sweet maize cultivars (BR-401 and BR-402), separately classified according to thickness, by using slotted screen sieves $(8 / 64$ " $\mathrm{x}$ $3 / 4,9 / 64$ " x 3/4, 10/64" x 3/4, 11/64" x 3/4, 12/64" x 3/4 and $13 / 64$ " $\mathrm{x} 3 / 4)$, and width, with round screen sieves (17/64", 18/64", 19/64", 20/64", 21/64" and 22/64"). For each cultivar, sorted lots were compared with the unrated batch, following a completely randomized design, in a $2 \times 7$ factorial scheme, with four replications. The biometric parameters evaluated were sieve retention, 100 seeds weight and water content. The physiologic quality was determined according to the first counting, germination, cold test, accelerated aging, electric conductivity and seedling emergence in the field. The classification with sieves improved the physiologic quality of sweet maize seeds. Seeds with intermediate thickness, for both cultivars, generally presented greater vigor. Concerning width, larger seeds, for the BR-401 cultivar, and intermediate seeds, for the BR-402 cultivar, showed better physiologic quality.
\end{abstract}

KEY-WORDS: Zea mays L.; seed classification; germination; seedling emergence.

\section{INTRODUÇÃO}

O milho doce é um dos vegetais mais populares nos Estados Unidos e Canadá, sendo, tradicionalmente, consumido in natura (Bordallo et al. 2005), enlatado ou congelado, na forma de espiga ou grãos (Oliveira Júnior et al. 2006).

\section{RESUMO}

As sementes de milho doce apresentam qualidade fisiológica inferior à das sementes de milho comum, devido à influência de várias características, como o tamanho e a forma das sementes. Diante disto, este estudo objetivou avaliar a qualidade fisiológica de sementes de duas cultivares de milho doce (BR-401 e BR-402), classificadas, separadamente, quanto à espessura, por meio de peneiras de crivos oblongos $(8 / 64$ " $\mathrm{x}$ $3 / 4,9 / 64$ ” x 3/4, 10/64" x 3/4, 11/64" x 3/4, 12/64" x 3/4 e $13 / 64$ " x 3/4), e quanto à largura, em peneiras de crivos redondos (17/64", 18/64", 19/64", 20/64", 21/64" e 22/64"). Para cada cultivar, os lotes classificados foram comparados com o lote sem classificação, seguindo delineamento inteiramente casualizado, em esquema fatorial $2 \times 7$, com quatro repetições. Os parâmetros biométricos avaliados foram: retenção em peneira, massa de 100 sementes e teor de água. A qualidade fisiológica foi determinada por meio da primeira contagem, germinação, teste de frio, envelhecimento acelerado, condutividade elétrica e emergência de plântulas no campo. A classificação em peneiras melhorou a qualidade fisiológica das sementes de milho doce. As sementes com espessura intermediária, para ambas as cultivares, em geral, apresentaram maior vigor. Quanto à largura, sementes maiores, para a cultivar BR-401, e de largura intermediária, para a cultivar BR-402, apresentaram melhor qualidade fisiológica.

PALAVRAS-CHAVE: Zea mays L.; classificação de sementes; germinação; emergência de plântulas.

Esse tipo de milho difere do comum por apresentar elevado teor de açúcares no endosperma, principalmente no estádio imaturo. A ação de alelos de genes mutantes, destacando-se o sugary $\left(\mathrm{su}_{1}\right)$, brittle $\left(\mathrm{bt}_{2}\right)$ e shrunken $\left(\mathrm{sh}_{2}\right)$, é responsável pela mudança no metabolismo deste vegetal, pois bloqueia a conversão de açúcares em amido (Araújo et al. 2006).

1. Trabalho recebido em set./2013 e aceito para publicação em mar./2014 ( $\mathrm{n}^{\mathrm{o}}$ registro: PAT 26648).

2. Universidade Estadual de Londrina (UEL), Centro de Ciências Agrárias, Departamento de Agronomia, Londrina, PR, Brasil.

E-mails: claudemircca@uel.br, cristian_brzezinski@yahoo.com.br.

3. Universidade Federal do Maranhão (UFMA), Departamento de Fitotecnia e Fitossanidade, São Luís, MA, Brasil. E-mail:jmguiscem@cca.uema.br.

4. Empresa Brasileira de Pesquisa Agropecuária, Embrapa Soja, Londrina, PR, Brasil. E-mail: fernando.henning@embrapa.br.

5. Universidade Estadual Paulista "Júlio de Mesquita Filho" (Unesp), Departamento de Produção Vegetal, Botucatu, SP, Brasil. E-mail: secdamv@fca.unesp.br. 
Estes genes provocam mudanças na qualidade do grão (sabor, aroma, maciez, textura e composição química), na aparência da planta e da espiga e na qualidade fisiológica das sementes (Tracy 2001, Guiscem et al. 2002).

A demanda nacional por milho doce vem crescendo, devido à existência de um mercado consumidor mais exigente, quanto à qualidade deste produto. Porém, um dos entraves para a expansão da produção no País é que as sementes apresentam problemas de baixa qualidade fisiológica, quando comparadas ao milho comum. Relaciona-se este problema à reduzida quantidade de amido e maior quantidade de açúcares no endosperma, que acarretam a formação de espaços entre a camada de aleurona e o pericarpo da semente, durante a maturação, deixando-a enrrugada. A fina espessura do pericarpo e a maturidade incompleta dos grãos também contribuem com os problemas fisiológicos (Kwiatkowski \& Clemente 2007).

Além das características genéticas, outros fatores podem afetar a qualidade fisiológica de sementes de milho doce, tais como época de colheita, temperatura de secagem dos grãos, danos mecânicos, ataque de pragas e doenças (Guiscem et al. 2003, Araújo et al. 2006, Gomes Júnior et al. 2009) e tamanho e forma das sementes.

O tamanho da semente pode influenciar diretamente na germinação e vigor das plântulas, devido ao fato de as sementes de maior tamanho ou densidade possuírem, normalmente, embriões bem formados e com maiores quantidades de reservas, sendo, potencialmente, mais vigorosas (Carvalho \& Nakagawa 2000). Contudo, sementes maiores, normalmente, estão mais sujeitas a danos mecânicos, no processo de beneficiamento (Peske et al. 2003).

Trabalhos científicos têm sido conduzidos, visando a associar as características de tamanho e massa de sementes com o seu desempenho, em testes de laboratório e em condições de campo. Carneiro et al. (2003), trabalhando com a influência do tamanho de sementes de milho pipoca na sua qualidade fisiológica, demonstraram que sementes maiores apresentaram melhor germinação e vigor. Já Vanzolini \& Nakagawa (2007) relataram que, geralmente, as sementes menores germinaram mais rapidamente, porém, as maiores originaram plântulas de maior tamanho e massa.

Quando é realizada a classificação das sementes, uma das características com maior grau de variabilidade em um lote é o tamanho, definido pelo com- primento, largura e espessura (Carvalho \& Nakagawa 2000). A classificação, normalmente, é realizada para facilitar e uniformizar a semeadura, além de interferir no ajuste das semeadoras (Paiva et al. 2006).

Diante do exposto, este estudo objetivou avaliar a qualidade fisiológica de sementes de duas cultivares de milho doce, em função da classificação quanto à espessura e largura.

\section{MATERIAL E MÉTODOS}

O trabalho foi desenvolvido no Laboratório de Fitotecnia da Universidade Estadual de Londrina (UEL), utilizando-se sementes produzidas no agrícola 2011/2012.

As sementes de duas cultivares de milho doce (BR-401 e BR-402) foram classificadas separadamente, quanto à espessura, em peneiras de crivos oblongos, descartando-se as classes inferiores a 8/64" $\mathrm{x}$ $3 / 4$ e sendo tomadas, para avaliação, seis classes de sementes [8/64" x 3/4 (P8), 9/64" x 3/4 (P9), 10/64" x 3/4 (P10), 11/64" x 3/4 (P11), 12/64" x 3/4 (P12) e $13 / 64$ " x 3/4 (P13)], e quanto à largura, em peneiras de crivos redondos, descartando-se as classes inferiores a 17/64" e tomando-se, para avaliação, seis classes de sementes [17/64" (P17), 18/64" (P18), 19/64" (P19), 20/64" (P20), 21/64" (P21) e 22/64" (P22)]. Para cada cultivar, os lotes obtidos na classificação das sementes foram comparados com o lote sem classificação (P0), seguindo-se delineamento experimental inteiramente casualizado, em esquema fatorial 2x7 (duas cultivares $\mathrm{x}$ sete classificações de sementes), com quatro repetições.

Após classificadas, as sementes foram submetidas às seguintes determinações:

a) Retenção em peneira: percentagem de sementes retidas em cada peneira;

b) Massa de 100 sementes: obtida com oito repetições de 100 sementes por tratamento (Brasil 2009), sendo os resultados expressos em gramas;

c) Teor de água: avaliado pelo método da estufa a $105 \pm 3^{\circ} \mathrm{C}$, com quatro repetições de 25 sementes por tratamento, durante 24 horas (Brasil 2009), sendo os resultados expressos em percentagem de umidade, em base úmida;

d) Primeira contagem do teste de germinação: percentagem de plântulas normais, aos quatro dias após a instalação do teste de germinação;

e) Teste de germinação: conduzido com quatro subamostras de 50 sementes por tratamento, coloca- 
das para germinar entre três folhas de papel-toalha embebidas com água destilada, na proporção de 2,5 vezes a massa do papel seco. Foram confeccionados rolos, os quais foram levados para um germinador do tipo Mangelsdorf, regulado para manter temperatura constante de $25^{\circ} \mathrm{C}$. As avaliações foram realizadas aos sete dias (contagem final), computando-se a percentagem de plântulas normais (Brasil 2009);

f) Teste de frio: realizado com quatro subamostras de 50 sementes por tratamento, sendo utilizadas, como substrato, três folhas de papel-toalha umedecidas com água destilada. Sobre estas, foi realizada a semeadura. Foram confeccionados rolos, os quais foram envoltos por sacos plásticos e lacrados com fita adesiva, permanecendo, nesta condição, por um período de sete dias, em câmara fria regulada à temperatura constante de $10^{\circ} \mathrm{C}$. Posteriormente, os rolos foram levados para germinador regulado à temperatura constante de $25^{\circ} \mathrm{C}$, onde permaneceram durante sete dias (Krzyzanowski et al. 1999). Os resultados foram expressos em percentagem (Brasil 2009);

g) Envelhecimento acelerado: realizado com quatro repetições de 65 sementes, para cada tratamento, utilizando-se caixas plásticas do tipo Gerbox, adaptadas com tela metálica. No seu interior, abaixo da tela, foram adicionados $40 \mathrm{~mL}$ de água destilada, para formar uma câmara úmida, e, sobre a tela, distribuíram-se as sementes, em camada única. Em seguida, as caixas foram fechadas, lacradas com fita crepe e mantidas em câmara de água jaquetada (water jacked incubator), regulada à temperatura constante de $42^{\circ} \mathrm{C}$, por um período de 72 horas (Dias \& Barros 1995). Quatro repetições de 15 sementes foram utilizadas para determinação do teor de água, após o envelhecimento, e quatro repetições de 50 sementes submetidas ao teste de germinação;

h) Condutividade elétrica: avaliada utilizando-se quatro repetições de 50 sementes, para cada tratamento. Inicialmente, foram eliminadas as sementes com trincas e/ou fraturas visíveis. Posteriormente, foram pesadas e colocadas em copos plásticos contendo $75 \mathrm{~mL}$ de água deionizada e, então, levadas a uma estufa incubadora, regulada à temperatura de $25^{\circ} \mathrm{C}$, por um período de 24 horas. Ao final deste período, foi efetuada a leitura, e os resultados foram expressos em $\mu \mathrm{S} \mathrm{cm}{ }^{1} \mathrm{~g}^{1}$ de sementes (Vieira \& Krzyzanowski 1999).

i) Emergência de plântulas no campo: foram utilizadas quatro subamostras de 50 sementes por tratamento, semeadas em sulco com $2,5 \mathrm{~m}$ de compri- mento e, aproximadamente, $0,03 \mathrm{~m}$ de profundidade. A contagem das plântulas normais emergidas foi realizada aos 10 dias após a semeadura e os resultados convertidos em percentagem (Nakagawa 1999).

Os dados obtidos foram submetidos à análise de variância, pelo teste de significância $F(p>0,05)$, e as médias comparadas pelo teste Tukey, a 5\%, sem transformação dos dados.

\section{RESULTADOS E DISCUSSÃO}

Os resultados obtidos na classificação por espessura demonstraram que houve maior percentagem de sementes retidas nas peneiras 9 e 10, para ambas as cultivares. Para o teor de água inicial, houve diferenças entre todas as peneiras estudadas, com os maiores teores para a BR-401 e os menores para a BR-402. Em relação às peneiras, para a cultivar BR-401, as sementes retidas na peneira 9 apresentaram maior teor de água, em relação às demais. Já para a BR-402, diferenças significativas foram constatadas apenas nas peneiras 8, 10 e 12 (Tabela 1).

Quanto à massa de 100 sementes, a cultivar BR-402 apresentou melhores resultados, em relação à BR-401, sendo que as sementes retidas nas peneiras maiores (13) apresentaram maior massa, em relação às demais (Tabela 1).

Na primeira contagem do teste de germinação, observou-se, para a cultivar BR-401, que o lote sem classificação (peneira 0) apresentou maior percentagem de germinação. Já para a cultivar BR-402, maior percentagem foi verificada nas sementes classificadas na peneira 10 , demonstrando que as sementes intermediárias apresentaram maior velocidade de germinação e, consequentemente, maior vigor. Entre as cultivares, foi constatada maior percentagem de germinação para a BR-401, para as sementes retidas nas peneiras $0,9,10$ e 12 (Tabela 1 ).

Com relação ao teste de germinação, houve diferença entre as cultivares somente para as sementes não classificadas, em que as sementes da cultivar BR-401 obtiveram maior percentagem de germinação, demonstrando, com isto, que a classificação das sementes não alterou a percentagem de germinação. Para a cultivar BR-402, percentagem de germinação inferior foi constatada em sementes retidas na peneira 13 , porém, apesar de não ocorrerem diferenças significativas, observou-se que as sementes classificadas em peneiras de menor e maior tamanho apresentaram menor percentagem de germinação (Tabela 1), dis- 
Tabela 1. Dados de retenção em peneira (RP), teor de água inicial (TA), massa de cem sementes (M100), primeira contagem do teste de germinação $(\mathrm{PC})$ e germinação $(\mathrm{G})$ de sementes de duas cultivares de milho doce, classificadas pela espessura (Londrina, PR, 2012).

\begin{tabular}{|c|c|c|c|c|c|c|c|c|c|c|}
\hline \multirow{2}{*}{ Peneira } & \multicolumn{2}{|c|}{ RP (\%) } & \multicolumn{2}{|c|}{ TA (\%) } & \multicolumn{2}{|c|}{ M100 (g) } & \multicolumn{2}{|c|}{ PC (\%) } & \multicolumn{2}{|c|}{ G (\%) } \\
\hline & BR-401 & BR-402 & BR-401 & BR-402 & BR-401 & BR-402 & BR-401 & BR-402 & BR-401 & BR-402 \\
\hline P0 & 100,0 & 100,0 & $8,5 \mathrm{aB}$ & $7,5 \mathrm{bAB}$ & $19,1 \mathrm{bD}$ & $20,5 \mathrm{aC}$ & $72 \mathrm{aA}$ & $21 \mathrm{bC}$ & $95 \mathrm{aA}$ & $90 \mathrm{bAB}$ \\
\hline P8 & 12,3 & 12,0 & $8,5 \mathrm{aB}$ & 7,7 bA & $15,4 \mathrm{bF}$ & $16,9 \mathrm{aE}$ & $43 \mathrm{aC}$ & $37 \mathrm{aB}$ & $92 \mathrm{aA}$ & $93 \mathrm{aAB}$ \\
\hline P9 & 25,8 & 23,8 & $9,0 \mathrm{aA}$ & 7,6 bAB & $17,6 \mathrm{bE}$ & $19,3 \mathrm{aD}$ & $59 \mathrm{aB}$ & $46 \mathrm{bAB}$ & $95 \mathrm{aA}$ & $94 \mathrm{aAB}$ \\
\hline P10 & 26,1 & 27,2 & $8,5 \mathrm{aB}$ & $7,2 \mathrm{bB}$ & $19,5 \mathrm{bCD}$ & $20,8 \mathrm{aC}$ & $59 \mathrm{aB}$ & $50 \mathrm{bA}$ & $97 \mathrm{aA}$ & $95 \mathrm{aA}$ \\
\hline P11 & 13,1 & 15,7 & $8,4 \mathrm{aB}$ & 7,3 bAB & $20,4 \mathrm{bAB}$ & $22,0 \mathrm{aAB}$ & $44 \mathrm{aC}$ & $37 \mathrm{aB}$ & $95 \mathrm{aA}$ & $95 \mathrm{aA}$ \\
\hline P12 & 7,8 & 9,8 & $8,6 \mathrm{aB}$ & $7,2 \mathrm{bB}$ & $20,1 \mathrm{bBC}$ & $21,6 \mathrm{aB}$ & $35 \mathrm{aC}$ & $23 \mathrm{bC}$ & $93 \mathrm{aA}$ & $90 \mathrm{aAB}$ \\
\hline $\mathrm{P} 13$ & 12,6 & 10,6 & $8,4 \mathrm{aB}$ & 7,5 bAB & $21,0 \mathrm{bA}$ & $22,5 \mathrm{aA}$ & $20 \mathrm{aD}$ & $15 \mathrm{baC}$ & $91 \mathrm{aA}$ & $88 \mathrm{aB}$ \\
\hline $\mathrm{CV}(\%)$ & & & \multicolumn{2}{|c|}{2,28} & \multicolumn{2}{|c|}{2,66} & \multicolumn{2}{|c|}{13,24} & \multicolumn{2}{|c|}{3,26} \\
\hline
\end{tabular}

Médias seguidas pela mesma letra, minúscula na linha e maiúscula na coluna, não diferem entre si, pelo teste Tukey $(\mathrm{p}>0,05)$.

cordando de Carneiro et al. (2003), que constataram que sementes de milho pipoca de formato plano e de tamanhos maiores apresentaram maiores valores de germinação. Todavia, todos os valores obtidos para esta variável apresentaram-se acima do padrão estabelecido para comercialização de sementes de milho doce, que exige germinação mínima de $75 \%$ (Brasil 2013).

Por meio do teste de frio, foi verificado que a cultivar BR-401 apresentou sementes com maior vigor, em relação à BR-402 (Tabela 2). Para as peneiras, não foram observadas diferenças. Resultados semelhantes foram obtidos por Martinelli-Seneme et al. (2000), os quais não encontraram diferenças significativas para vigor (teste de frio e emergência a campo), em sementes de milho de diferentes classes de tamanho.

O teste de envelhecimento acelerado indicou diferenças no vigor entre as cultivares, para as sementes não classificadas e retidas nas peneiras $9 \mathrm{e}$
13, sendo que as sementes da BR-401 apresentaram maior vigor, em relação à $\mathrm{BR}-402$. Na comparação entre peneiras, diferenças foram verificadas apenas para a cultivar BR-402, com menor vigor para as sementes oriundas das peneiras 13 e não classificada (Tabela 2). Esta diferença pode ter ocorrido devido ao fato de as sementes de maior tamanho apresentarem maior susceptibilidade a danos mecânicos, porém, quando latentes, estes danos somente podem ser detectados por meio de testes que simulem o processo de armazenamento, como o envelhecimento acelerado. Delouche (1972) cita que o dano latente não afeta, de imediato, a viabilidade das sementes, porém, durante o armazenamento, as sementes injuriadas sofrem redução na germinação e no vigor, com reflexos negativos no potencial de armazenamento e no desempenho das plantas no campo.

O teor de água, após o teste de envelhecimento acelerado, variou $28,8-32,5 \%$, para a cultivar BR-401, e 28,5-35,7\%, para a BR-402, demonstran-

Tabela 2. Dados do teste de frio (TF), teste de envelhecimento acelerado (EA), teor de água após o envelhecimento acelerado (TAAE), teste de condutividade elétrica (CE) e percentagem de emergência de plântulas no campo (EC) de sementes de duas cultivares de milho doce, classificadas pela espessura (Londrina, PR, 2012).

\begin{tabular}{|c|c|c|c|c|c|c|c|c|c|c|}
\hline \multirow{2}{*}{ Peneira } & \multicolumn{2}{|c|}{ TF (\%) } & \multicolumn{2}{|c|}{ EA (\%) } & \multicolumn{2}{|c|}{ TAAE (\%) } & \multicolumn{2}{|c|}{$\mathrm{CE}\left(\mu \mathrm{S} \mathrm{cm}{ }^{1} \mathrm{~g}^{1}\right)$} & \multicolumn{2}{|c|}{ EC (\%) } \\
\hline & BR-401 & BR-402 & BR-401 & BR-402 & BR-401 & BR-402 & BR-401 & BR-402 & BR-401 & BR-402 \\
\hline P0 & $59 \mathrm{aA}$ & $24 \mathrm{bA}$ & $69 \mathrm{aA}$ & $38 \mathrm{bB}$ & $31,5 \mathrm{bA}$ & $33,5 \mathrm{aBC}$ & $21,5 \mathrm{aA}$ & $19,2 \mathrm{aA}$ & $45 \mathrm{bB}$ & $70 \mathrm{aA}$ \\
\hline P8 & $60 \mathrm{aA}$ & $37 \mathrm{bA}$ & $84 \mathrm{aA}$ & $74 \mathrm{aA}$ & $32,5 \mathrm{bA}$ & $35,7 \mathrm{aA}$ & $24,2 \mathrm{bA}$ & $19,4 \mathrm{aA}$ & $85 \mathrm{aA}$ & $77 \mathrm{aA}$ \\
\hline P9 & $75 \mathrm{aA}$ & $33 \mathrm{bA}$ & $82 \mathrm{aA}$ & $57 \mathrm{bAB}$ & $31,5 \mathrm{aA}$ & $31,6 \mathrm{aCD}$ & $21,6 \mathrm{bA}$ & $18,6 \mathrm{aA}$ & $80 \mathrm{aA}$ & $73 \mathrm{aA}$ \\
\hline P10 & $76 \mathrm{aA}$ & $31 \mathrm{bA}$ & $78 \mathrm{aA}$ & $74 \mathrm{aA}$ & 29,4 bBC & $33,7 \mathrm{aAB}$ & $21,0 \mathrm{bA}$ & $14,8 \mathrm{aA}$ & $59 \mathrm{aB}$ & $68 \mathrm{aA}$ \\
\hline P11 & $75 \mathrm{aA}$ & $35 \mathrm{bA}$ & $77 \mathrm{aA}$ & $66 \mathrm{aA}$ & $31,1 \mathrm{bAB}$ & $32,5 \mathrm{aBC}$ & $20,5 \mathrm{bA}$ & $16,2 \mathrm{aA}$ & $51 \mathrm{bB}$ & $84 \mathrm{aA}$ \\
\hline P12 & $70 \mathrm{aA}$ & $28 \mathrm{bA}$ & $73 \mathrm{aA}$ & $65 \mathrm{aA}$ & $28,8 \mathrm{aC}$ & $28,5 \mathrm{aE}$ & $26,1 \mathrm{bA}$ & $19,3 \mathrm{aA}$ & $57 \mathrm{bB}$ & $80 \mathrm{aA}$ \\
\hline P13 & $74 \mathrm{aA}$ & $34 \mathrm{bA}$ & $68 \mathrm{aA}$ & $37 \mathrm{bB}$ & $28,8 \mathrm{aC}$ & $29,8 \mathrm{aDE}$ & $21,1 \mathrm{bA}$ & $16,2 \mathrm{aA}$ & $60 \mathrm{bB}$ & $76 \mathrm{aA}$ \\
\hline CV (\%) & \multicolumn{2}{|c|}{26,69} & \multicolumn{2}{|c|}{14,09} & \multicolumn{2}{|c|}{2,99} & \multicolumn{2}{|c|}{14,27} & \multicolumn{2}{|c|}{12,60} \\
\hline
\end{tabular}

Médias seguidas pela mesma letra, minúscula na linha e maiúscula na coluna, não diferem entre si, pelo teste Tukey ( $\mathrm{p}>0,05)$. 
do, assim, que somente sementes da BR-401 não apresentaram variação entre amostras superior a 4\%. Segundo Marcos Filho (1999), sob estas condições, o teste pode ser considerado uniforme.

Para a condutividade elétrica, não foi constatada diferença significativa na classificação entre as peneiras, dentro das cultivares. Aguilera et al. (2000), trabalhando com qualidade fisiológica de sementes de milho, em função da forma e tratamento químico, não verificaram diferenças de vigor entre lotes, com a aplicação do teste de condutividade elétrica. $\mathrm{Na}$ comparação entre peneiras, foi observado que, para a cultivar BR-401, somente o lote sem classificação não diferiu da BR-402, sendo que, para os demais, a BR-401 apresentou os maiores valores e, consequentemente, menor vigor, em relação à BR-402 (Tabela 2). Esta diferença de vigor entre as cultivares pode estar relacionada a diversos fatores, como percentagem de sementes mal formadas, ocorrência de doenças e insetos, condições ambientais desfavoráveis durante a fase de produção, ou maior deterioração no campo, devido a possíveis atrasos na colheita (Marcos Filho 2005).

Quanto à emergência de plântulas no campo, diferenças entre as cultivares foram observadas nas peneiras $0,11,12$ e 13, com menores percentagens para a BR-401. Também foi verificado que as peneiras de menor tamanho (8 e 9) resultaram em percentagens de emergência superiores às demais (Tabela 2). O efeito do tamanho sobre a emergência de plântulas também foi observado por Santos et al. (2005), em sementes de soja da cultivar Splendor, ao verificarem que sementes retidas nas peneiras de menor tamanho apresentaram maiores percentagens de emergência em campo, em relação às de maior tamanho. Já Gaspar \& Nakagawa (2002) e Araújo et al. (2004) observaram que sementes de maior tamanho têm proporcionado maiores percentagens finais de emergência.

Quando classificadas pela largura, ambas as cultivares avaliadas apresentaram maiores percentagens de sementes retidas nas peneiras 19 e 20 e menores nas peneiras 17 e 22 (Tabela 3). O teor de água variou significativamente entre as cultivares, em todas as peneiras avaliadas (Tabela 3), porém, as diferenças constatadas não foram superiores a $1 \%$, não interferindo, assim, nos processos biológicos das sementes, pois, sob baixos conteúdos de água, a atividade metabólica nas sementes é reduzida (Castro \& Hilhorst 2004).

Quando comparadas pela largura, a cultivar BR-401 apresentou maior massa de 100 sementes, em relação à BR-402, sendo inferior a esta apenas em sementes do lote não classificado. Para ambas as cultivares, houve aumento na massa, à medida em que se aumentou a largura, variando de 17,1 a 23,0, para a BR-401, e de 14,8 a 22,3, para a BR-402.

Em relação à primeira contagem do teste de germinação, ocorreram diferenças entre as cultivares, para as sementes não classificadas e das peneiras 20 e 22 , sendo que a cultivar BR-401 apresentou maiores percentagens de plântulas normais, em relação à BR-402. As peneiras somente influenciaram nos resultados da primeira contagem para a cultivar BR-402, sendo que as sementes provenientes das peneiras menores apresentaram maior número de sementes germinadas e, consequentemente, maior vigor, demonstrando, com isto, que o tamanho afeta a velocidade de germinação das sementes (Tabela 3).

Tabela 3. Dados de retenção em peneira (RP), teor de água inicial (TA), massa de cem sementes (M100), primeira contagem do teste de germinação (PC) e germinação $(\mathrm{G})$ de sementes de duas cultivares de milho doce, classificadas pela largura (Londrina, PR, 2012).

\begin{tabular}{|c|c|c|c|c|c|c|c|c|c|c|}
\hline \multirow{2}{*}{ Peneira } & \multicolumn{2}{|c|}{ RP (\%) } & \multicolumn{2}{|c|}{ TA(\%) } & \multicolumn{2}{|c|}{ M100 (g) } & \multicolumn{2}{|c|}{ PC (\%) } & \multicolumn{2}{|c|}{ G (\%) } \\
\hline & BR-401 & BR-402 & BR-401 & BR-402 & BR-401 & BR-402 & BR-401 & BR-402 & BR-401 & BR-402 \\
\hline P0 & 100,0 & 100,0 & $8,5 \mathrm{aA}$ & $7,5 \mathrm{bD}$ & $19,1 \mathrm{bD}$ & $20,5 \mathrm{aB}$ & $73 \mathrm{aA}$ & $22 \mathrm{bD}$ & $95 \mathrm{aA}$ & $90 \mathrm{aA}$ \\
\hline P17 & 6,1 & 7,8 & $7,7 \mathrm{bB}$ & $8,3 \mathrm{aA}$ & $17,1 \mathrm{aF}$ & $14,8 \mathrm{bF}$ & $61 \mathrm{aA}$ & $63 \mathrm{aAB}$ & $89 \mathrm{aA}$ & $74 \mathrm{bB}$ \\
\hline P18 & 12,8 & 14,5 & $7,7 \mathrm{bB}$ & $8,1 \mathrm{aABC}$ & $18,6 \mathrm{aE}$ & $16,8 \mathrm{bE}$ & $69 \mathrm{aA}$ & $61 \mathrm{aAB}$ & $91 \mathrm{aA}$ & $74 \mathrm{bB}$ \\
\hline P19 & 20,9 & 19,8 & $7,6 \mathrm{bB}$ & 7,9 aC & $19,8 \mathrm{aD}$ & $18,1 \mathrm{bD}$ & $69 \mathrm{aA}$ & $66 \mathrm{aA}$ & $90 \mathrm{aA}$ & $95 \mathrm{aA}$ \\
\hline P20 & 18,1 & 18,2 & $7,7 \mathrm{bB}$ & $8,0 \mathrm{aBC}$ & $20,9 \mathrm{aC}$ & $19,0 \mathrm{bC}$ & $69 \mathrm{aA}$ & $48 \mathrm{bBC}$ & $89 \mathrm{aA}$ & $95 \mathrm{aA}$ \\
\hline P21 & 16,9 & 14,5 & $7,6 \mathrm{bB}$ & $8,2 \mathrm{aAB}$ & $21,9 \mathrm{aB}$ & $20,4 \mathrm{bB}$ & $62 \mathrm{aA}$ & $58 \mathrm{aAB}$ & $94 \mathrm{aA}$ & $95 \mathrm{aA}$ \\
\hline $\mathrm{P} 22$ & 12,4 & 11,0 & $7,7 \mathrm{bB}$ & $8,0 \mathrm{aBC}$ & $23,0 \mathrm{aA}$ & $22,3 \mathrm{bA}$ & $67 \mathrm{aA}$ & $33 \mathrm{bCD}$ & $97 \mathrm{aA}$ & $93 \mathrm{aA}$ \\
\hline CV (\%) & & & \multicolumn{2}{|c|}{1,38} & \multicolumn{2}{|c|}{2,20} & \multicolumn{2}{|c|}{13,65} & \multicolumn{2}{|c|}{5,25} \\
\hline
\end{tabular}


As cultivares avaliadas apresentaram altas percentagens de germinação, na classificação pela largura, com valores superiores aos padrões estabelecidos para comercialização (Tabela 3). Apenas nas peneiras 17 e 18 houve diferenças entre as cultivares, com percentagens inferiores para a BR-402, em relação à BR-401. Entre as peneiras, foi constatada diferença apenas para a BR-402, com menores percentagens de germinação para as sementes provenientes das peneiras de menor tamanho (17 e 18). Com estes resultados, é possível observar que, apesar de as sementes menores apresentarem maior vigor na primeira contagem do teste de germinação, ao final do período de avaliação, este comportamento não é observado, principalmente devido à sua reduzida quantidade de reserva, que proporciona menor número de plantas normais, ao final da avaliação, em relação às sementes com maiores quantidades de reservas. Gaspar \& Nakagawa (2002), trabalhando com sementes de milheto, verificaram que a germinação e o vigor desta espécie são influenciados pelo tamanho, sendo que as sementes maiores apresentaram melhores resultados de germinação e vigor, em relação às menores.

Quanto ao teste de frio, houve diferença para as sementes sem classificação e das peneiras 18 e 22, sendo que a BR-401 mostrou-se superior à BR-402 (Tabela 4). Em ambas as cultivares, o tratamento sem classificação diferiu dos demais, com menores percentagens de germinação. O teste de frio é o teste de vigor mais utilizado para milho e tem, como princípio básico, a exposição das sementes a baixa temperatura, alta umidade e agentes patogênicos, funcionando como instrumento de grande valor para a seleção prévia de lotes de sementes, quanto ao seu desempenho, em uma ampla faixa de condições ambientais (Barros et al. 1999).

$\mathrm{O}$ teste de envelhecimento acelerado indicou diferenças entre as cultivares, para as peneiras 18 , 19, 22 e sementes sem classificação, sendo que a BR-401 apresentou resultados superiores à BR-402, exceto para as sementes retidas na peneira 18. Para a cultivar BR-401, a maior e menor percentagem de germinação após o envelhecimento foram observadas nas sementes das peneiras 22 e 18 , respectivamente. Já para a cultivar BR-402, menores percentagens de germinação foram verificadas nas sementes não classificadas e na peneira 22 .

Os teores de água, após o envelhecimento acelerado, não diferiram entre os fatores estudados, indicando uniformidade nas condições, durante o teste (Tabela 4).

Para a condutividade elétrica, houve diferença nas sementes retidas na peneira 17 , com menor valor para a BR-402. Já para as demais, não foi encontrada diferença significativa (Tabela 4). Houve relação entre o teor de água inicial das sementes e os valores de condutividade, pois as cultivares que apresentaram menor teor de água inicial obtiveram maiores valores de condutividade. Rosa et al. (2000) observaram que quanto maior o teor de água nas sementes de milho, no início do teste de condutividade elétrica, maior o vigor das sementes. Estes resultados devem estar relacionados com o processo de reorganização da dupla camada lipídica da membrana celular, em função do processo de reidratação da semente. Assim, quanto menor o teor de água da semente, maior o estado de desorganização da membrana celular, logo, maior o tempo necessário para que ocorra a reorganização

Tabela 4. Dados do teste de frio (TF), teste de envelhecimento acelerado (EA), teor de água após o envelhecimento acelerado (TAAE), teste de condutividade elétrica (CE) e percentagem de emergência de plântulas no campo (EC) de sementes de duas cultivares de milho doce, classificadas pela largura (Londrina, PR, 2012).

\begin{tabular}{|c|c|c|c|c|c|c|c|c|c|c|}
\hline \multirow{2}{*}{ Peneira } & \multicolumn{2}{|c|}{ TF (\%) } & \multicolumn{2}{|c|}{ EA (\%) } & \multicolumn{2}{|c|}{ TAAE (\%) } & \multicolumn{2}{|c|}{$\mathrm{CE}\left(\mu \mathrm{S} \mathrm{cm} \mathrm{cm}^{1}\right)$} & \multicolumn{2}{|c|}{ EC (\%) } \\
\hline & BR-401 & BR-402 & BR-401 & BR-402 & BR-401 & BR-402 & BR-401 & BR-402 & BR-401 & BR-402 \\
\hline P0 & $49 \mathrm{aB}$ & $24 \mathrm{bB}$ & $69 \mathrm{aABC}$ & $38 \mathrm{bC}$ & $33,1 \mathrm{aA}$ & $31,5 \mathrm{aA}$ & $21,5 \mathrm{aA}$ & $19,2 \mathrm{aA}$ & $46 \mathrm{bA}$ & $71 \mathrm{aA}$ \\
\hline P17 & $71 \mathrm{aA}$ & $59 \mathrm{aA}$ & 69 aABC & $63 \mathrm{aA}$ & $34,7 \mathrm{aA}$ & $33,7 \mathrm{aA}$ & $26,5 \mathrm{bA}$ & $16,9 \mathrm{aA}$ & $51 \mathrm{bA}$ & $73 \mathrm{aA}$ \\
\hline P18 & $84 \mathrm{aA}$ & $65 \mathrm{bA}$ & $51 \mathrm{bC}$ & $71 \mathrm{aA}$ & $33,0 \mathrm{aA}$ & $32,2 \mathrm{aA}$ & $19,3 \mathrm{aA}$ & $17,6 \mathrm{aA}$ & $64 \mathrm{aA}$ & $67 \mathrm{aA}$ \\
\hline P19 & $74 \mathrm{aA}$ & $63 \mathrm{aA}$ & $76 \mathrm{aAB}$ & $61 \mathrm{bAB}$ & $33,8 \mathrm{aA}$ & $33,2 \mathrm{aA}$ & $22,5 \mathrm{aA}$ & $16,9 \mathrm{aA}$ & $50 \mathrm{bA}$ & $76 \mathrm{aA}$ \\
\hline P20 & $81 \mathrm{aA}$ & $68 \mathrm{aA}$ & $73 \mathrm{aAB}$ & $65 \mathrm{aA}$ & $32,9 \mathrm{aA}$ & $31,1 \mathrm{aA}$ & $23,7 \mathrm{aA}$ & 18,9 aA & $58 \mathrm{bA}$ & $80 \mathrm{aA}$ \\
\hline $\mathrm{P} 21$ & $65 \mathrm{aAB}$ & $68 \mathrm{aA}$ & $59 \mathrm{aBC}$ & $62 \mathrm{aAB}$ & $33,4 \mathrm{aA}$ & $31,4 \mathrm{aA}$ & $21,7 \mathrm{aA}$ & $15,6 \mathrm{aA}$ & $57 \mathrm{bA}$ & $74 \mathrm{aA}$ \\
\hline $\mathrm{P} 22$ & $85 \mathrm{aA}$ & $66 \mathrm{bA}$ & $80 \mathrm{aA}$ & $42 \mathrm{bBC}$ & $32,8 \mathrm{aA}$ & $31,2 \mathrm{aA}$ & $16,8 \mathrm{aA}$ & $18,2 \mathrm{aA}$ & $60 \mathrm{aA}$ & $69 \mathrm{aA}$ \\
\hline CV (\%) & \multicolumn{2}{|c|}{14,16} & \multicolumn{2}{|c|}{15,16} & \multicolumn{2}{|c|}{4,10} & \multicolumn{2}{|c|}{22,88} & \multicolumn{2}{|c|}{16,39} \\
\hline
\end{tabular}

Médias seguidas pela mesma letra, minúscula na linha e maiúscula na coluna, não diferem entre si, pelo teste Tukey ( $\mathrm{p}>0,05)$. 
desta e, consequentemente, menor a lixiviação de solutos (Bewley \& Black 1985).

Para a emergência de plântulas no campo, as cultivares diferiram somente nas sementes retidas nas peneiras 18 e 22, sendo a BR-402 superior à BR-401. Na comparação entre peneiras, não houve diferenças, quanto à percentagem de emergência de plântulas no campo (Tabela 4). Resultados semelhantes foram obtidos por Sangoi et al. (2004), trabalhando com sementes de diferentes tamanhos e profundidades de semeadura, na cultura do milho, em que os autores não observaram diferenças na percentagem de plantas emergidas 10 dias após a semeadura. Forsthofer et al. (2003) observaram resultados similares, em sementes de seis híbridos de milho com tamanhos contrastantes.

As diferenças observadas entre as cultivares podem ser explicadas pelo ciclo de produção, pois a cultivar BR-402 apresenta ciclo mais tardio (95 dias), em relação à BR-401 (80 dias). Assim, as sementes podem ficar mais tempo expostas a condições adversas, antes da colheita, fato que afeta a sua qualidade.

Foi observada alta incidência de fungos, principalmente no teste de envelhecimento acelerado, sendo esta, possivelmente, um dos fatores responsáveis pela redução na qualidade fisiológica das sementes da cultivar BR-402. Segundo Henning (2005), os problemas de ocorrência de condições climáticas desfavoráveis, chuvas e altas temperaturas, durante as fases de maturação e colheita, afetam a qualidade fisiológica e sanitária das sementes. França Neto et al. (2006) relataram que a presença de certos patógenos pode causar efeitos diretos à qualidade das sementes, como a redução do seu potencial germinativo.

Em geral, a classificação em peneiras melhorou a qualidade fisiológica das sementes de milho doce, sendo que as de tamanho intermediário apresentaram maior vigor, em relação às demais, principalmente em virtude de as sementes de maior tamanho apresentarem maior susceptibilidade a danos mecânicos, durante a colheita e o beneficiamento, e as de menor tamanho reduzidas quantidades de reservas no endosperma (Carvalho \& Nakagawa 2000).

\section{CONCLUSÕES}

1. A classificação em peneiras melhorou a qualidade fisiológica das sementes de milho doce.

2. Sementes com espessura intermediária, para ambas as cultivares, em geral, apresentaram maior vigor.
3. Sementes de milho doce de maior largura, para a cultivar BR-401, e de largura intermediária, para a cultivar BR-402, apresentaram melhor qualidade fisiológica.

\section{REFERÊNCIAS}

AGUILERA, L. A. et al. Qualidade fisiológica de sementes de milho em função da forma e do tratamento químico das sementes. Ciência Rural, Santa Maria, v. 30, n. 2, p. 211-215, 2000.

ARAÚJO, E. F. et al. Maturação de sementes de milhodoce: grupo superdoce. Revista Brasileira de Sementes, Londrina, v. 28, n. 2, p. 69-76, 2006.

ARAÚJO, E. F. et al. Uso de peneiras e da mesa gravitacional na classificação e na qualidade de sementes de cafeeiro (Coffea arabica L.). Revista Brasileira de Armazenamento, Viçosa, v. 8, n. 1, p. 24-28, 2004.

BARROS, S. R. B. et al. Teste de frio. In: KRZYZANOWSKI, F. C.; VIEIRA, R. D.; FRANÇA NETO, J. B. (Eds.). Vigor de sementes: conceitos e testes. Londrina: Abrates, 1999. p. 5.1-5.15.

BEWLEY, J. D.; BLACK, M. Seeds: physiology of development and germination. New York: Plenum Press, 1985.

BORDALLO, P. N. et al. Análise dialélica de genótipos de milho doce e comum para caracteres agronômicos e proteína total. Horticultura Brasileira, Brasília, DF, v. 23, n. 1, p. 123-127, 2005.

BRASIL. Ministério da Agricultura, Pecuária e Abastecimento. Instrução Normativa $\mathrm{N}^{\circ} 45$, de 17 de setembro de 2013. Padrões para produção e comercialização de sementes de milho. 2013. Disponível em: <http:www. abrasem.com.br>. Acesso em: 11 mar. 2014.

BRASIL. Ministério da Agricultura, Pecuária e Abastecimento. Regras para análise de sementes. Brasília, DF: MAPA/ACS, 2009.

CARNEIRO, V. et al. Efeito da debulha e da classificação sobre o tamanho e a qualidade de sementes de milho pipoca. Revista Brasileira de Milho e Sorgo, Sete Lagoas, v. 2, n. 1, p. 97-105, 2003.

CARVALHO, N. M.; NAKAGAWA, J. Sementes: ciência, tecnologia e produção. Jaboticabal: Funep, 2000.

CASTRO, R. D.; HILHORST, R. H. W. M. Embebição e reativação do metabolismo. In: FERREIRA, A. G.; BORGHETTI, F. Germinação: do básico ao aplicado. Porto Alegre: Artmed, 2004. p. 149-162.

DELOUCHE, J. C. Seed deterioration: notes on seed deterioration. Jackson: Mississipi State University, 1972. 
DIAS, M. C. L. L.; BARROS, A. S. R. Avaliação da qualidade de sementes de milho. Londrina: Iapar, 1995. (Circular, 88).

FORSTHOFER, E. L. et al. Emergência e desenvolvimento inicial de seis híbridos de milho em função de tamanho de sementes, profundidade de semeadura e de temperatura de solo. In: REUNIÃO TÉCNICA ANUAL DO MILHO, 48., 2003, Porto Alegre. Anais... Porto Alegre: Fepagro, 2003. 1 CD-ROM.

FRANÇA NETO, J. B. et al. Tecnologia da produção de sementes de soja de alta qualidade. Londrina: Foros, 2006.

GASPAR, C. M.; NAKAGAWA, J. Influência do tamanho na germinação e no vigor de sementes de milheto (Penninsetum americum (L.) Leeke). Revista Brasileira de Sementes, Londrina, v. 24, n. 1, p. 339-344, 2002.

GOMES JÚNIOR, F. G. et al. Evaluation of priming effects on sweet corn seeds by SVIS. Seed Technology, Washington, DC, v. 31, n. 1, p. 95-100, 2009.

GUISCEM, J. M. et al. Qualidade fisiológica de sementes de milho doce BR 401 (su) em função do teor de água na colheita e da temperatura de secagem. Semina: Ciências Agrárias, Londrina, v. 24, n. 2, p. 243-254, 2003.

GUISCEM, J. M.; NAKAGAWA, J.; ZUCARELLI, C. Qualidade fisiológica de sementes de milho doce BR 400 (BT) em função do teor de água na colheita e da temperatura de secagem. Revista Brasileira de Sementes, Londrina, v. 24, n. 1, p. 220-228, 2002.

HENNING, A. A. Patologia e tratamento de sementes: noções gerais. 2. ed. Londrina: Embrapa Soja, 2005. (Documentos, 264).

KRZYZANOWSKI, F. C.; VIEIRA, R. D.; FRANÇA NETO, J. B. Vigor de sementes: conceitos e testes. Londrina: Abrates, 1999.

KWIATKOWSKI, A; CLEMENTE, E. Características do milho doce (Zea mays L.) para industrialização. Revista Brasileira de Tecnologia Agroindustrial, Ponta Grossa, v. 1, n. 2, p. 93-103, 2007.

MARCOS FILHO, J. Fisiologia de sementes de plantas cultivadas. Piracicaba: Fealq, 2005.

MARCOS FILHO, J. Testes de vigor: importância e utilização. In: KRZYZANOWSKI, F. C.; VIEIRA, R. D.; FRANÇA NETO, J. B. (Eds.). Vigor de sementes: conceitos e testes. Londrina: Abrates, 1999. p. 1-24.

MARTINELLI-SENEME, A.; ZANOTTO, M. D.; NAKAGAWA, J. Efeito da forma e do tamanho da semente na produtividade do milho cultivar AL-34. Revista Brasileira de Sementes, Londrina, v. 22, n. 1, p. 232-238, 2000.
NAKAGAWA, J. Testes de vigor baseados no desempenho de plântulas. In: KRZYZANOWSKI, F. C.; VIEIRA, R. D.; FRANÇA NETO, J. B. Vigor de sementes: conceitos e testes. Londrina: Abrates, 1999. p. 2.1-2.24.

OLIVEIRA JÚNIOR, L. F. G. et al. Seleção de genótipos de milho mais promissores para o consumo in natura. Revista da Sociedade Brasileira de Ciência e Tecnologia de Alimentos, Campinas, v. 26, n. 1, p. 159-166, 2006.

PAIVA, B. M. de; ALVES, R. M.; HELENO, N. M. Aspecto socioeconômico da soja. Informe Agropecuário, Belo Horizonte, v. 27, n. 230, p. 7-14, 2006.

PESKE, S. T. et al. Sementes: fundamentos científicos e tecnológicos. Pelotas: Ed. Universitária, 2003.

ROSA, S. D. V. F. et al. Eficácia do teste de condutividade elétrica para uso em estudos de danos de secagem em sementes de milho. Revista Brasileira de Sementes, Londrina, v. 22, n. 1, p. 54-63, 2000.

SANGOI, L. et al. Tamanho de semente, profundidade de semeadura e crescimento inicial do milho em duas épocas de semeadura. Revista Brasileira de Milho e Sorgo, Sete Lagoas, v. 3, n. 3, p. 370-380, 2004.

SANTOS, P. M. et al. Efeito da classificação por tamanho da semente de soja na sua qualidade fisiológica durante o armazenamento. Acta Scientiarum Agronomy, Maringá, v. 27, n. 3, p. 395-402, 2005.

TRACY, W. F. Sweet corn. In: HALLAUER, A. R. (Ed.). Specialty corns. 2. ed. Boca Raton: CRC Press, 2001. p. 155-197.

VANZOLINI, S.; NAKAGAWA, J. Testes de vigor baseados no desempenho de plântulas. Informativo Abrates, Londrina, v. 17, n. 1-3, p. 76-83, 2007.

VIEIRA, R. D.; KRZYZANOWSKI, F. C. Teste de condutividade elétrica. In: KRZYZANOWSKI, F. C.; VIEIRA, R. D.; FRANÇA NETO, J. B. (Eds.). Vigor de sementes: conceitos e testes. Londrina: Abrates, 1999. p. 4.1- 4.26. 